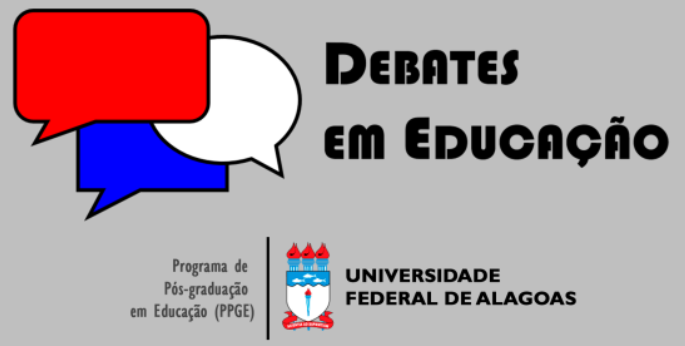

ISSN Eletrônico 2175-6600

Vol. 12 | N. 28 | Set./Dez. | 2020

Ivana Almeida Serpa

9 iD

Universidade Estadual do Rio Grande do Sul (UERGS)

ivana.serpal@gmail.com

Débora Velasque de Souza

9 ID

Universidade Federal do Pampa (UNIPAMPA) deboravelasquel4@gmail.com

Eliane de Lourdes Fontana Piffero

(9) ID

Universidade Federal do Pampa (UNIPAMPA) ailtondinardi@gmail.com

Ailton Jesus Dinardi

9 ID

Universidade Federal do Pampa (UNIPAMPA) elianefontanapiffero@gmail.com

\section{A GESTÃO ESCOLAR E A FORMAÇÃO DE PROFESSORES: INTERLOCUÇÕES E POSSIBILIDADES}

\section{RESUMO}

A gestão democrática escolar busca proporcionar espaços cooperativos de formação profissional dos educadores que compõem a equipe. Diante da relevância de discutir sobre a temática, o presente artigo objetivou desenvolver uma análise teóricoreflexiva sobre os processos de gestão democrática e a formação docente no contexto escolar. $\bigcirc$ caminho metodológico adotado foi a pesquisa bibliográfica, a fim de dar suporte teórico ao estudo com base em autores como Libâneo (20 I 5), Veiga (20।3), Tardif (20 |7), Tardif e Lessard (20 |4), Gatti (20।3), Nóvoa (20।3, 20 I4) e Luck (2017). A partir das análises empreendidas, conclui-se que a gestão escolar democrática deve fazer da escola um lugar de autonomia docente, tornando os profissionais protagonistas de seu próprio aperfeiçoamento constante.

Palavras-chave: Formação docente. Gestão democrática. Políticas Educacionais.

\section{SCHOOL MANAGEMENT AND TEACHER EDUCATION: INTERLOCUTIONS AND POSSIBILITIES}

\section{ABSTRACT}

Democratic school management seeks to provide cooperative spaces for the professional training of educators who make up the team. Given the relevance of discussing the theme, this article aimed to develop a theoretical-reflexive analysis on the processes of democratic management and teacher education in the school context. The methodological approach adopted was bibliographic research, in order to provide theoretical support to the study based on authors such as Libâneo (20 I 5), Veiga (20 |3), Tardif (20 |7), Tardif and Lessard (20 |4), Gatti (20 I3), Nóvoa. (20।3, 2014) and Luck (2017). From the analyzes undertaken, it is concluded that the democratic school management should make the school a place of teaching autonomy, making the professionals protagonists of their own constant improvement.

Keywords: Teacher education. Democratic management. Educational policies.

Submetido em: 03/01/2020

Aceito em: 17/06/2020

Publicado em: 18/08/2020

dc http://dx.doi.org// 0.28998/2 I 75-6600.2020v I 2n28p543-553 


\section{INTRODUÇÃO}

A gestão escolar, conforme as legislações e documentos que regem a educação nacional, deve desenvolver suas atividades sociopolíticas em um viés democrático a fim de envolver a comunidade escolar nas múltiplas discussões que permeiam o espaço educativo. Dentre as atribuições da equipe gestora das instituições, está prevista a elaboração e o apoio à realização de programas de formação inicial e continuada de professores, pois segundo a Lei de Diretrizes e Bases da Educação Nacional (LDB), n 9394/96, legislação educacional que regulamenta a educação pública, em seu Art. 62., "§l ${ }^{\circ}$ A União, o Distrito Federal, os Estados e os Municípios, em regime de colaboração, deverão promover a formação inicial, a continuada e a capacitação dos profissionais de magistério" (BRASIL, 1996).

Diante da relevância de discutir a temática, realizou-se o presente estudo que tem por objetivo desenvolver uma análise teórico-reflexiva sobre os processos de gestão democrática e formação docente no contexto escolar. A partir do objetivo proposto, foi delineado o seguinte problema central que orienta esse estudo: como os processos de gestão democrática e a formação de professores estão sendo problematizados por investigadores do campo educacional?

Com o intuito de buscar discutir e responder à problematização, metodologicamente foi realizada uma pesquisa de abordagem qualitativa, que se caracteriza pelo envolvimento subjetivo do investigador diante das relações sociais que se constroem ao longo da realização do estudo, sem a necessidade de analisar gráfica ou numericamente (GIL, 20 I7). Além disso, as discussões pertinentes à compreensão e ao estudo acerca do assunto foram construídas a partir de pesquisa bibliográfica, procedimento técnico que visa analisar pesquisas e estudos acadêmicos sobre o assunto utilizando autores e pesquisadores referência sobre a temática (GIL, 2017).

Sendo assim, foi estruturada a primeira seção, Gestão democrática escolar: diálogos entre as Políticas educacionais e os Processos Educativos, visando aprofundar o estudo acerca da gestão educativa. A seguir é abordada a formação docente, na seção intitulada $A$ formação continuada de professores como potencializadora do trabalho pedagógico. Por último, em uma terceira seção, sob o título A gestão democrática e a formação de professores no contexto escolar, discute-se como se articulam esses processos na escola.

\section{GESTÃO DEMOCRÁTICA ESCOLAR: DIÁLOGOS ENTRE AS POLÍTICAS EDUCACIONAIS E OS PROCESSOS EDUCATIVOS}

A instituição escolar é um espaço público constituído de múltiplas relações sociais e culturais que deve compartilhar e distribuir as inúmeras responsabilidades e atribuições aos envolvidos no processo 
educativo. Através da cooperação que deve ser incentivada pela gestão escolar, todos os segmentos devem ter voz ativa no processo de decisão e discussão dos caminhos e desafios pedagógicos enfrentados pela comunidade: docentes, familiares e estudantes. Essa função se mostra como sendo essencial para construir a autonomia administrativa e pedagógica da escola baseada no diálogo (VEIGA, 2013).

A gestão escolar, em uma perspectiva participativa, pressupõe a contribuição e a colaboração da comunidade, mas é importante ressaltar que requer atitudes e ações tendo em vista os objetivos buscados pela coletividade, de forma a tornar possível uma relação entre teorias e práticas que ocorram efetivamente. Nesse sentido, Luck (2017, p. 44) afirma que: “[...] participar implica compartilhar poder, responsabilidades por decisões tomadas em conjunto com uma coletividade e o enfrentamento dos desafios de promoção de avanços, no sentido da melhoria contínua e transformações necessárias".

A fim de promover a participação coletiva, foi estabelecido na Constituição de 1988, dentre os princípios que permeiam o ensino público, o seguinte modelo de gestão cooperativa apresentado no artigo 206, inciso VI, que defende a "gestão democrática do ensino público, na forma da lei" (BRASIL, 1988). Assim, fica evidente que as escolas devem garantir práticas de gestão descentralizadas que resultem em ações participativas que aproximem todos os envolvidos no contexto escolar.

Além disso, a LDB também fortalece e evidencia a importância de constituir espaços democráticos de decisões e vínculos com a comunidade escolar, salientando em seu artigo I 4, que os sistemas de ensino deverão garantir a Gestão democrática do ensino com base nos seguintes princípios: I- participação dos profissionais da educação na elaboração do projeto pedagógico da escola; II - participação das comunidades escolar e local em conselhos escolares ou equivalentes (BRASIL, 1996).

Nesse sentido, propõe a construção do projeto político-pedagógico (PPP) das escolas, que deve considerar as especificidades pertencentes à cultura local e contar com a participação e contribuição dos professores, gestores, comunidade, funcionários e alunos que fazem parte do cotidiano das instituições e conhecem as necessidades a serem contempladas no projeto. A partir dessa ideia, Veiga (20I3) ressalva que o PPP é um documento capaz de constituir a identidade da escola, bem como sua autonomia, tornando-a um espaço público de debates, diálogo e reflexão coletiva.

A identidade da escola, seus princípios, concepções, objetivos e metas educativas passam a ser conhecidas e discutidas por toda a comunidade escolar, de forma que as principais necessidades sejam contempladas no projeto pedagógico da escola, conforme Veiga (20 I 3, p. I I) "entendido como a própria organização do trabalho pedagógico como um todo". Além disso, devem ser considerados para a análise da qualidade das práticas educativas, a partir da construção coletiva do projeto pedagógico, os seguintes elementos internos da escola salientados por Silva (20 I 8, p. 224): 
Esse fazer democrático refletido nas decisões coletivas que acontecem na escola é fortalecido pelos órgãos colegiados e projetos desenvolvidos que contam com o apoio dos diversos segmentos representativos da escola, além de estar presente em outras políticas educacionais, como o Plano Nacional de Educação (PNE) (BRASIL, 20|4). Esse documento apresenta metas e estratégias que possibilitam o alcance dos números e resultados almejados quanto à qualidade da educação pública ofertada, compreendendo o período de 2014 a 2024 para efetivar as 20 metas elencadas.

Com relação à garantia da gestão democrática escolar, o PNE estabelece a importância da participação da comunidade escolar na eleição de diretores, para que os representantes assumam e busquem solucionar os principais problemas e metas defendidas pela comunidade, constituindo a cidadania no ensino público. Diante do exposto, a meta 19 pretende assegurar condições:

[...] para a efetivação da gestão democrática da Educação, associada a critérios técnicos de mérito e desempenho e consulta pública à comunidade escolar, no âmbito das escolas públicas, prevendo recursos e apoio técnico da União para tanto (BRASIL, 20I4).

Segundo Bordignon; Gracindo (2004, p. 147), a gestão democrática escolar é um dos princípios pedagógicos em evidência nas políticas educacionais apresentadas anteriormente, uma vez que "a gestão transforma metas e objetivos educacionais em ações, dando concretude às direções traçadas pelas políticas". Diante disso, o modelo coletivo de gestão na organização pedagógica das instituições escolares torna-se um ponto estratégico para a concretização das melhorias necessárias para cada contexto escolar.

Nesse sentido, é preciso articular as distintas esferas - administrativa, pedagógica e financeira - que perpassam o processo educacional, salientando a importância da cooperação mútua entre todos os envolvidos. Cabe salientar que para alcançar esse fim, segundo Veiga (2013, p. 17), é preciso haver "uma ruptura histórica na prática administrativa da escola". Implica, portanto, traçar um esforço coletivo na busca por concretizar a autonomia política e administrativa, capaz de apontar caminhos em direção à construção de um espaço plural, flexível e democrático.

\section{A FORMAÇÃO DE PROFESSORES COMO POTENCIALIZADORA DO TRABALHO PEDAGÓGICO}

Esta ruptura histórica da prática administrativa, citado por Veiga (20 I 3), de forma direta ou indireta, possibilitará a abertura de espaços para avanços na qualidade do processo educativo desenvolvido na escola.

A qualidade da educação ofertada está interligada com o preparo profissional da equipe docente para a realização de seu trabalho na escola e com o direito dos profissionais da educação ao aperfeiçoamento constante de suas práticas. A valorização do trabalho pedagógico, nesse sentido, requer 
estratégias que permitam e possibilitem a indissociabilidade entre as teorizações estudadas ao longo das práticas pedagógicas e as experiências advindas de sua atuação na escola, uma vez que, para Gatti (20 I3, p. 97), "práticas geram teorizações e teorizações geram práticas".

A formação inicial compreende a aproximação com a realidade escolar, a partir dos saberes construídos em instituições formadoras de professores, ao passo que a formação continuada é uma aprendizagem constante perante as reflexões sobre as próprias experiências no espaço escolar, portanto, adquirida através do trabalho e da socialização profissional. A formação continuada evidencia uma bagagem de conhecimentos que constituem a identidade dos professores. Na visão de Tardif (2017, p. 33), os saberes dos professores se constituem, "na verdade, de vários saberes provenientes de diferentes fontes. Esses saberes são os saberes disciplinares, curriculares, profissionais [...] e experienciais".

Evidentemente, essa relação entre os saberes docentes se fortalece nas oportunidades de formação de professores, no que diz respeito à formação inicial e à formação continuada. A formação docente, como direito dos profissionais da educação, é garantida pela LDB, especialmente no artigo 62, parágrafo primeiro, ao estabelecer que "a União, o Distrito Federal, os Estados e os Municípios, em regime de colaboração, deverão promover a formação inicial, a continuada e a capacitação dos profissionais de magistério" (BRASIL, 1996).

A fim de promover a formação inicial de professores em nível superior, o PNE propôs uma meta para garantir a criação de uma Política Nacional de Formaç̧ão dos Profissionais da Educação, assegurando que os docentes em exercício na Educação Básica "possuam formação específica de nível superior, obtida em curso de licenciatura na área de conhecimento em que atuam" (BRASIL, 20|4). Dessa forma, fica evidente a preocupação em proporcionar formação em nível de graduação de qualidade, com o devido preparo para trabalhar no ensino público. Quanto à formação continuada, o PNE prevê, na Meta I6:

Formar, em nível de pós-graduação, 50\% dos professores da Educação Básica, até o último ano de vigência deste PNE, e garantir a todos os (as) profissionais da Educação Básica formação continuada em sua área de atuação, considerando as necessidades, demandas e contextualizações dos sistemas de ensino (BRASIL, 20I4).

A meta defende o aperfeiçoamento constante em articulação com as especificidades da escola, bem como as necessidades e prioridades educacionais de cada comunidade escolar. Percebe-se, diante disso, que os documentos oficiais e as pesquisas acadêmicas demonstram a importância de conquistar formação docente de qualidade para melhorar os processos de ensino-aprendizagem na Educação Básica, já que o trabalho pedagógico incide diretamente na aprendizagem dos estudantes.

A luta se fortalece na direção de formar os professores para que possam aliar os conhecimentos teóricos estudados nas instituições universitárias às práticas pedagógicas que são desenvolvidas no espaço escolar, de forma que sejam profissionais críticos, reflexivos e pesquisadores do campo educacional, não 
meros reprodutores das mazelas presentes nas políticas de formação docente. É necessário, segundo Pimenta e Lima (2017, p. 7):

[...] trabalhar a teoria como expressão da prática e fazer desta um espaço de problematização é um desafio a ser defendido e conquistado [...]; essa postura reflexiva nem sempre se encontra nos cursos de formação de professores. Na maioria desses cursos há profunda dicotomia entre as disciplinas pedagógicas e as das áreas específicas.

Nessa perspectiva, compreende-se a importância de articular os saberes pedagógicos aos conhecimentos específicos de cada área curricular, fortalecendo a formação inicial e pressupondo caminhos contrários à fragmentação do trabalho educativo. Gatti (2013) corrobora com essa ideia ao defender que há uma predominância da formação disciplinar específica sobre os saberes pedagógicos na formação inicial de professores, uma vez que esse conhecimento didático será indispensável para a atuação desses profissionais em sala de aula.

Com isso, a formação docente deve ser fortalecida através de vínculos entre as universidades formadoras e entre as escolas, de forma que esse diálogo favoreça e incentive uma prática reflexiva possível, a partir da atuação no interior das instituições de ensino. Segundo Nóvoa (2013, p. 203), essa articulação é capaz de potencializar os conhecimentos docentes, visando à "procura de um conhecimento profissional, que não é mera aplicação prática de qualquer teoria, mas que exige um esforço próprio de elaboração e reelaboração".

A partir desses entendimentos e discussões, fica claro o quanto é fundamental a conquista de uma política de formação de professores que realmente atenda as expectativas das escolas, em constante interação com a universidade, em uma perspectiva que valorize o papel dos professores na educação pública brasileira. Sabe-se que a atividade docente é uma profissão complexa, a qual exige amplas competências para a sua efetiva atuação.

A partir dessa constatação, Tardif e Lessard (2014, p. 9) apontam que "o ensino se tornou um trabalho especializado e complexo, uma atividade rigorosa, que exige, daqueles e daquelas que a exercem, a existência de um verdadeiro profissionalismo". Esse cenário reafirma a urgência da melhoria da qualidade da formação docente, tanto inicial quanto continuada, em razão da pluralidade de saberes que constituem a profissão professor.

\section{A GESTÃO DEMOCRÁTICA E A FORMAÇÃO DE PROFESSORES NO CONTEXTO ESCOLAR}

Ao se reportar à expansão do ensino público que teve seu auge nas últimas décadas, percebe-se a inserção de um número expressivo de professores, selecionados em um tempo limitado, os quais nem sempre foram profissionalmente capacitados para sua atuação (NÓVOA, 20।3). Com base nisso, a gestão 
escolar, em diálogo com a comunidade, deve propor estratégias que visem ao aperfeiçoamento constante da equipe docente, levando em consideração os desafios que precisam ser superados por meio de um trabalho pedagógico de qualidade, considerando que a formação continuada dos profissionais da educação incide diretamente na conquista de avanços significativos nos processos de ensino e de aprendizagem. Diante disso, no entender de Veiga (2013, p. 20):

[...] a escola deve realizar o levantamento de necessidades de formação continuada de seus profissionais; elaborar seu programa de formação, contando com a participação e apoio dos órgãos centrais, no sentido de fortalecer seu papel na concepção, na execução e na avaliação.

A partir dessas indicações, pode-se inferir que esse deve ser um compromisso assumido pela escola em busca da formação qualificada dos profissionais, já que esse espaço educativo é um campo de pesquisa predominante, de reflexão sobre as práticas. Além disso, é preciso constituir vínculos com universidades e instituições de formação de professores que possam contribuir com cursos que visem à formação continuada dos profissionais, de acordo com a realidade e com o contexto escolar. Em consonância com esse pensamento, Nóvoa (2013, p. 205) defende "a criação de uma nova realidade organizacional no interior da qual estejam integrados os professores e os formadores de professores (universitários)".

Nesse cenário, pode-se destacar que a formação se constitui também com a partilha de experiências entre os docentes que possuem distintas trajetórias profissionais, uma vez que essa interação pressupõe uma troca de vivências, teorias e práticas que podem potencializar o processo de ensino e aprendizagem. Nessa perspectiva, segundo Tardif (2017, p. 52), "o docente é não apenas um prático, mas também um formador".

Logo, essas estratégias de qualificação docente podem fomentar os saberes que constituem os conhecimentos necessários para a atuação educativa, que são organizados por Tardif (2017, p. 36) em quatro saberes que compõem a docência, sendo estes: "saberes oriundos da formação profissional, de saberes disciplinares, curriculares e experienciais". Dessa maneira, a articulação desses saberes poderá subsidiar uma relação entre teorias e práticas que sustente um trabalho comprometido com a realidade escolar. Esse processo se constitui ao longo da formação inicial e continuada dos professores, integrando experiências, conhecimentos específicos e pedagógicos.

Nesse sentido, Grigoli et. al. (2010) afirmam a importância dos gestores em valorizar e incentivar a formação continuada dos professores, a partir da construção de uma escola democrática, rompendo com os obstáculos que impedem essa democratização, buscando promover ações que fortaleçam os vínculos de apoio entre o corpo docente, além de estreitar o diálogo entre escola e comunidade.

O papel do gestor, segundo as autoras, é fundamental no sentido de incentivar a formação continuada a partir da escola, como centro do processo de reflexão sobre as práticas. A gestão democrática 
participativa, nesse sentido, busca promover o desenvolvimento e a formação de todos os envolvidos nas práticas pedagógicas e escolares, através das trocas de experiências, saberes, soluções e concepções educativas para alcançar coletivamente os objetivos e metas da instituição de ensino.

Segundo Domingues (2015, p. |16), a criação e construção de projetos voltados ao desenvolvimento profissional no espaço escolar "aproximam-se da concepção de que os professores, os coordenadores pedagógicos, os diretores e os outros membros da comunidade escolar constituem-se em protagonistas de sua ação". Ainda nessa perspectiva, Nóvoa (20।4) salienta que é preciso constituir uma autonomia profissional docente que valorize as habilidades específicas da docência, extremamente desprezadas no cenário atual.

Em suma, nesta perspectiva de formação a partir da escola e da gestão compartilhada e participativa, os profissionais são estimulados a construir e reconstruir conhecimentos e concepções pedagógicas de trabalho ao levar em conta tanto suas experiências individuais, quanto as bagagens formativas dos demais envolvidos no processo educativo. Essas reflexões sobre as práticas e projetos desenvolvidos na escola devem ser permeadas por discussões embasadas teoricamente em articulação aos aspectos didáticos e metodológicos intrínsecos ao ato de ensinar.

Assim sendo, os profissionais em constante aperfeiçoamento passam, Segundo Libâneo (20 I 5, p. 19), a ter "domínio da área pedagógica em temas ligados ao processo ensino-aprendizagem, ao currículo, às relações professor-aluno e dos alunos entre si, aos métodos e procedimentos didáticos, incluindo o uso da tecnologia educacional". Dessa forma, a realidade escolar que se manifesta no espaço educativo, com suas especificidades e identidade deve ser considerada nos percursos formativos com a equipe escolar que valorizam os diferentes saberes articulados no cotidiano. A escola assume cooperativamente suas responsabilidades administrativas, políticas e pedagógicas na formação dos cidadãos.

\section{CONSIDERAÇÕES FINAIS}

O problema de pesquisa que orientou a presente investigação buscou analisar como os processos de gestão escolar democrática e a formação de professores estão sendo problematizados por investigadores do campo educacional. De acordo com os teóricos da área, são apontados caminhos a serem concretizados pela gestão escolar, a fim de consolidar uma formação docente fundamentada na escola enquanto espaço de produção e compartilhamento de saberes.

A gestão democrática escolar, conforme o exposto no decorrer do presente artigo, mostra-se como um desafio a ser conquistado, tendo em vista a promoção da educação pública de qualidade. Embora existam inúmeras legislações que defendem a atuação de uma gestão democrática em âmbito educacional, percebe-se uma disparidade entre as políticas e as ações desenvolvidas nas escolas públicas. Nesse mesmo 
viés, as leis que garantem o direito a formações continuadas aos profissionais da educação devem se tornar instrumentos de reivindicação para que sejam efetivadas no contexto escolar.

A formação dos educadores, historicamente desvalorizada, traz consigo a ideia da incapacidade profissional de professores, em construir novos conhecimentos advindos de suas experiências individuais e coletivas. Visando romper com esse paradigma, devem-se fortalecer práticas reflexivas que contemplem os múltiplos saberes que permeiam sua trajetória profissional. Evidentemente, a formação profissional dos envolvidos na educação requer a valorização do trabalho pedagógico, através da construção da autonomia docente.

Nesse sentido, a garantia da formação continuada dos professores que atuam nas instituições de ensino é um caminho imprescindível para lutar contra as mazelas e desafios educacionais. A gestão escolar, nessa perspectiva, deve recorrer aos órgãos competentes a fim de efetivar as formações docentes, por meio de parcerias entre escolas, universidades e outras instituições de ensino, para implementar programas de capacitação inicial ou continuada. Essas interações promovem a melhoria do processo de ensino e aprendizagem, além de fazer da escola um espaço de produção científica em que as vivências do cotidiano se tornam novos conhecimentos pedagógicos.

Acredita-se que a escola é um espaço central de compartilhamento e construção de saberes. Sendo assim, almejar uma gestão democrática que a defenda como o principal locus da formação inicial e continuada é imprescindível para a valorização dos saberes docentes. É preciso fazer da escola pública um espaço democrático a fim de defendê-la como prioridade nas políticas e ações nacionais.

\section{REFERÊNCIAS}

BRASIL. Constituição da República Federativa do Brasil: promulgada em 5 de outubro de 1988.

Disponível em: http://www.planalto.gov.br/ccivil_03/Constituicao/Constituicao.htm Acesso em: 09 dez. 2018.

BRASIL. Lei n 9.394, de 20 de dezembro de 1996. Estabelece as diretrizes e bases da Educação Nacional. Brasília: Diário Oficial da União, Poder Executivo, 1996.

Disponível em: http://www.planalto.gov.br/ccivil_03/leis/L9394.htm Acesso em: 10 jan. 2017.

BRASIL. Lei n 13.005, de 25 de junho de 2014. Aprova o Plano Nacional de Educação - PNE e dá outras providências. Brasília: Diário Oficial da União, Poder Executivo, 25 jun. 20 14. Disponível em: http://www.planalto.gov.br/ccivil_03/ ato20 I I-2014/20 I4/lei/l I3005.htm Acesso em: 20 fev. 2017.

BRASIL. Caderno Conhecendo as 20 Metas do Plano Nacional de Educação. Brasília: MEC/SASE, 20 I 4. BORDIGNON, G.; GRACINDO, R. V. Gestão da educação: o município e a escola. In: FERREIRA, N. S. C.; AGUIAR, M. A. da S. Gestão da Educação: impasses, perspectivas e compromissos. São Paulo: 
Cortez, 2004. p. 147.

DOMINGUES, I. O coordenador pedagógico e a formação contínua do docente na escola. I ${ }^{a}$ ed. São Paulo: Cortez Editora, 2015.

GATTI, B. A. A prática pedagógica como núcleo do processo de formação de professores. In: GATTI, B. A. et al. Por uma política nacional de formação de professores. I ${ }^{a}$ ed. São Paulo: Editora Unesp. 2013. p. 95- 106.

GIL, A. C. Como elaborar projetos de pesquisa. 6ª ed. São Paulo: Atlas, 2017.

GRIGOLI, J. A. G. et al. A escola como lócus de formação docente: uma gestão bem-sucedida. Cadernos de Pesquisa, Fundação Carlos Chagas, v. 40, n. 139, p. 237-256, 20 I0. Disponível em: http://hdl.handle.net/I I449/27303 Acesso em: 13 jul. 2019.

LIBÂNEO, J. C. Formação de professores e didática para desenvolvimento humano. Educação \& Realidade, v. 40, n. 2, p. 629-650, 2015. Disponível em: http://www.scielo.br/pdf/edreal/20 I 5nahead/2 175-6236-edreal-46 I32.pdf Acesso em: I4 jun. 2019.

LUCK, H. A Gestão participativa na escola. Petrópolis: Vozes, 2017.

NÓVOA, A. Nada substitui um bom professor: propostas para uma revolução no campo da formação de professores. In: GATTI, B. A. et al. Por uma política nacional de formação de professores. $\left.\right|^{a}$ ed. São Paulo: Editora Unesp, 2013. p. 199-210.

NÓVOA, A. O passado e o presente dos professores. In: NÓVOA, A. (org.) et al. Profissão professor. $2^{a}$ ed. Portugal: Porto Editora, 2014.

PIMENTA, S. G.; LIMA, M. do S. L. Os (des)caminhos das políticas de formação de professores-o caso dos estágios supervisionados e o programa de iniciação à docência: duas faces da mesma moeda? In: REUNIÃO NACIONAL DA ASSOCIAÇÃO NACIONAL DE PÓS-GRADUAÇÃO E PESQUISA EM EDUCAÇÃO, 38, 20 17. Democracia em risco: A pesquisa e a pós-graduação em contexto de resistência. Anais... São Luís/MA: ANPED, 2017.

SILVA, M. A. da. Qualidade social da educação pública: algumas aproximações. Cadernos Cedes, v. 29, n. 78, p. 216-226, 2018. Disponível em:

https://www.ingentaconnect.com/content/doaj/0 I $013262 / 2018 / 00000029 / 00000078 /$ art00005 Acesso em: 14 jul. 2019.

TARDIF, M. Saberes docentes e formação profissional. Petrópolis: Vozes, 2017.

TARDIF, M.; LESSARD, C. (orgs.). O ofício de professor: Histórias, perspectivas e desafios internacionais. $6^{\mathrm{a}}$ ed. Petrópolis: Vozes, 2014.

VEIGA, I. A. Projeto Político-Pedagógico da escola: Uma construção possível. In: VEIGA, I. A. Projeto Político-Pedagógico da escola: uma construção coletiva. 29a ed. Campinas: Papirus, 20 I3. p. II -35. 


\section{COMO CITAR ESSE ARTIGO}

SERPA, Ivana Almeida et al. A gestão escolar e a formação de professores: interlocuções e possibilidades. Debates em Educação, Maceió, v. 12, n. 28, p. 543-553, Set./Dez. 2020. ISSN 2175-6600. Disponível em: https://www.seer.ufal.br/index.php/debateseducacao/article/view/9396. Acesso em: dd mmm. aaaa. 